\title{
Front Matter: Volume 10383
}

, "Front Matter: Volume 10383," Proc. SPIE 10383, Terahertz Emitters, Receivers, and Applications VIII, 1038301 (9 November 2017); doi: 10.1117/12.2296952

EDIE Event: SPIE Optical Engineering + Applications, 2017, San Diego, California, SPIE. United States 


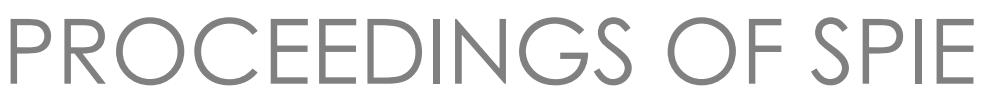

\title{
Terahertz Emitters, Receivers, and Applications VIII
}

\author{
Manijeh Razeghi \\ Alexei N. Baranov \\ Dimitris Pavlidis \\ John M. Zavada \\ Editors
}

6-7 August 2017
San Diego, California, United States

Sponsored and Published by

SPIE 
The papers in this volume were part of the technical conference cited on the cover and title page. Papers were selected and subject to review by the editors and conference program committee. Some conference presentations may not be available for publication. Additional papers and presentation recordings may be available online in the SPIE Digital Library at SPIEDigitalLibrary.org.

The papers reflect the work and thoughts of the authors and are published herein as submitted. The publisher is not responsible for the validity of the information or for any outcomes resulting from reliance thereon.

Please use the following format to cite material from these proceedings:

Author(s), "Title of Paper," in Terahertz Emitters, Receivers, and Applications VIII, edited by Manijeh Razeghi, Alexei N. Baranov, Dimitris Pavlidis, John M. Zavada, Proceedings of SPIE Vol. 10383 (SPIE, Bellingham, WA, 2017) Seven-digit Article CIID Number.

ISSN: 0277-786X

ISSN: 1996-756X (electronic)

ISBN: 9781510612235

ISBN: 9781510612242 (electronic)

Published by

SPIE

P.O. Box 10, Bellingham, Washington 98227-0010 USA

Telephone +1 3606763290 (Pacific Time) · Fax +1 3606471445

SPIE.org

Copyright (C) 2017, Society of Photo-Optical Instrumentation Engineers.

Copying of material in this book for internal or personal use, or for the internal or personal use of specific clients, beyond the fair use provisions granted by the U.S. Copyright Law is authorized by SPIE subject to payment of copying fees. The Transactional Reporting Service base fee for this volume is $\$ 18.00$ per article (or portion thereof), which should be paid directly to the Copyright Clearance Center (CCC), 222 Rosewood Drive, Danvers, MA 01923. Payment may also be made electronically through CCC Online at copyright.com. Other copying for republication, resale, advertising or promotion, or any form of systematic or multiple reproduction of any material in this book is prohibited except with permission in writing from the publisher. The CCC fee code is 0277$786 \mathrm{X} / 17 / \$ 18.00$.

Printed in the United States of America.

Publication of record for individual papers is online in the SPIE Digital Library.

\section{SPIE. DIGITAL}

Paper Numbering: Proceedings of SPIE follow an e-First publication model. A unique citation identifier (CID) number is assigned to each article at the time of publication. Utilization of CIDs allows articles to be fully citable as soon as they are published online, and connects the same identifier to all online and print versions of the publication. SPIE uses a seven-digit CID article numbering system structured as follows:

- The first five digits correspond to the SPIE volume number.

- The last two digits indicate publication order within the volume using a Base 36 numbering system employing both numerals and letters. These two-number sets start with $00,01,02,03$, 04, 05, 06, 07, 08, 09, 0A, OB ... 0Z, followed by 10-1Z, 20-2Z, etc. The CID Number appears on each page of the manuscript. 


\title{
Contents
}

\author{
$\checkmark$ Authors \\ vii Conference Committee \\ ix Introduction
}

SESSION 1 GENERATION OF THz RADIATION

1038303 Backward wave oscillator for high power generation at THz frequencies (Invited Paper) [10383-2]

SESSION 2 QCL THZ SOURCES

1038305 Terahertz emitters at Center for Quantum Devices: recent advances and future trends (Invited Paper) [10383-4]

\section{SESSION 3 NOVEL CONCEPTS AND MATERIALS FOR THz TECHNOLOGY}

10383 OA Design of a multistep phase mask for high-energy THz pulse generation in ZnTe crystal [10383-9]

SESSION 4 FUNDAMENTALS OF GENERATION, DETECTION, AND PROPAGATION OF THz WAVES I

10383 OC Temperature-driven massless fermions in $\mathrm{HgCdTe}$ heterostructures (Invited Paper) [10383-11]

10383 OD Complex delay dynamics of high power quantum cascade oscillators (Invited Paper) [10383-12]

$10383 \mathrm{OE}$ Characterization of THz wave generated from air plasma induced by two-color laser with long wavelength [10383-13]

\section{SESSION $5 \quad$ THz SPECTROSCOPY}

$10383 \mathrm{OH}$ Substance identification by pulsed THz spectroscopy in the presence of disordered structure (Invited Paper) [10383-16]

10383 0J Dual THz comb spectroscopy (Invited Paper) [10383-18] 
SESSION 6 FUNDAMENTALS OF GENERATION, DETECTION, AND PROPAGATION OF THz WAVES II

10383 OM Terahertz wave polyethylene lens based on wave front phase modulation [10383-21]

10383 ON Materials for $1.55 \mu \mathrm{m}$-pumped terahertz photoconductive switches: a review (Invited Paper) [10383-22]

SESSION 7 THz IMAGING

10383 OP Super-resolved terahertz microscopy by knife-edge scan [10383-24]

$103830 Q \quad$ Terahertz imaging for subsurface investigation of art paintings [10383-25]

10383 OS Compact solutions for spectroscopic solid-state-based terahertz imaging systems (Invited Paper) [10383-27]

POSTER SESSION

10383 OV Frequency division multiplexing THz light field imaging [10383-30] 


\section{Authors}

Numbers in the index correspond to the last two digits of the seven-digit citation identifier (CID) article numbering system used in Proceedings of SPIE. The first five digits reflect the volume number. Base 36 numbering is employed for the last two digits and indicates the order of articles within the volume. Numbers start with 00, 01, 02, 03, 04, 05, 06, 07, 08, 09, OA, OB...0Z, followed by 10-12, 20-2Z, etc.

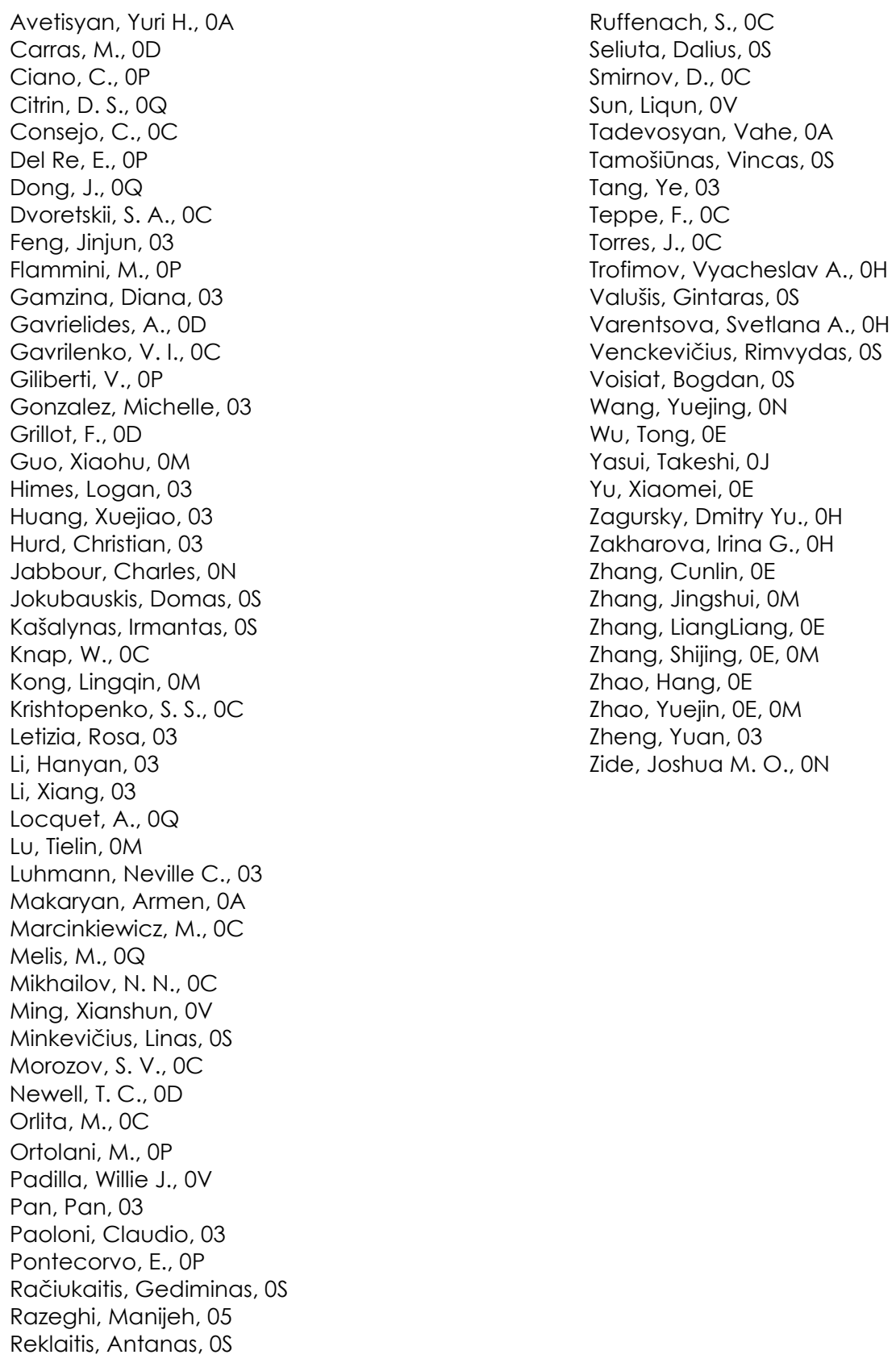

Ruffenach, S., OC

Seliuta, Dalius, OS

Smirnov, D., OC

Sun, Liqun, OV

Tadevosyan, Vahe, OA

Tamošiūnas, Vincas, OS

Tang, Ye, 03

Teppe, F., OC

Torres, J., OC

Trofimov, Vyacheslav A., $\mathrm{OH}$

Valušis, Gintaras, OS

Varentsova, Svetlana A., $\mathrm{OH}$

Venckevičius, Rimvydas, OS

Voisiat, Bogdan, OS

Wang, Yuejing, ON

$\mathrm{Wu}$, Tong, $\mathrm{OE}$

Yasui, Takeshi, 0J

Yu, Xiaomei, OE

Zagursky, Dmitry Yu., $\mathrm{OH}$

Zakharova, Irina G., $\mathrm{OH}$

Zhang, Cunlin, $\mathrm{OE}$

Zhang, Jingshui, OM

Zhang, LiangLiang, $\mathrm{OE}$

Zhang, Shijing, OE, OM

Zhao, Hang, $\mathrm{OE}$

Zhao, Yuejin, OE, OM

Zheng, Yuan, 03

Zide, Joshua M. O., ON 
Proc. of SPIE Vol. 10383 1038301-6

Downloaded From: https://www.spiedigitallibrary.org/conference-proceedings-of-spie on 26 Apr 2023 Terms of Use: https://www.spiedigitallibrary.org/terms-of-use 


\title{
Conference Committee
}

\author{
Conference Chairs
}

Manijeh Razeghi, Northwestern University (United States)

Alexei N. Baranov, Université Montpellier 2 (France)

Dimitris Pavlidis, National Science Foundation (United States)

John M. Zavada, Polytechnic Institute of New York University

(United States)

Program Track Chairs

Shizhuo Yin, The Pennsylvania State University (United States)

Ruyan Guo, The University of Texas at San Antonio (United States)

Conference Program Committee

Maria Amanti, Université Paris 7-Denis Diderot (France)

Richard D. Averitt, University of California, San Diego (United States)

Stefano Barbieri, Université Paris 7-Denis Diderot (France)

Robert J. Grasso, EOIR Technologies (United States)

Sven Höfling, University of St. Andrews (United Kingdom)

Hiroshi Ito, Kitasato University (Japan)

Wojciech Knap, Université Montpellier 2 (France)

Juliette Mangeney, Ecole Normale Supérieure (France)

Oleg Mitrofanov, University College London (United Kingdom)

Gaël Mouret, Université du Littoral Côte d'Opale (France)

Naoki Oda, NEC Corporation (Japan)

Mauro F. Pereira, Sheffield Hallam University (United Kingdom)

Edik U. Rafailov, Aston University (United Kingdom)

Pascale Roy, Synchrotron SOLEIL (France)

Gaetano Scamarcio, Universitá degli Studi di Bari Aldo Moro (Italy)

Carlo Sirtori, Université Paris 7-Denis Diderot (France)

Zachary D. Taylor, University of California, Los Angeles (United States)

Roland Teissier, Université Montpellier 2 (France)

Vladimir V. Vaks, Institute for Physics of Microstructures

(Russian Federation)

Gintaras Valušis, Center for Physical Sciences and Technology

(Lithuania)

Miriam S. Vitiello, Consiglio Nazionale delle Ricerche (Italy)

Benjamin S. Williams, University of California, Los Angeles

(United States) 


\section{Session Chairs}

1 Generation of $\mathrm{THz}$ Radiation

Alexei N. Baranov, University Montpellier (France)

Mauro F. Pereira, Sheffield Hallam University (United Kingdom)

2 QCL THz Sources

Edik U. Rafailov, Aston University (United Kingdom)

3 Novel Concepts and Materials for THz Technology

Mikhail A. Belkin, The University of Texas at Austin (United States)

Gintaras Valušis, Center for Physical Sciences and Technology (Lithuania)

4 Fundamentals of Generation, Detection, and Propagation of $\mathrm{THz}$ Waves I

Dmitry Turchinovich, Max-Planck-Institut für Polymerforschung (Germany)

Lyubov V. Titova, Worcester Polytechnic Institute (United States)

5 THz Spectroscopy

Diana Gamzina, SLAC National Accelerator Laboratory (United States)

6 Fundamentals of Generation, Detection, and Propagation of $\mathrm{THz}$ Waves II

Frédéric Grillot, Télécom ParisTech (France)

Robert J. Grasso, EOIR Technologies (United States)

$7 \quad$ THz Imaging

Manijeh Razeghi, Northwestern University (United States)

John M. Zavada, Polytechnic Institute of New York University (United States) 


\section{Introduction}

\section{Why do we need THz and where are we now?}

The terahertz $(\mathrm{THz})$ spectral range $(1-10 \mathrm{THz})$ is bridging the gap between the visible/infrared photonics and the high frequency electronics, where both disciplines are stuck by their marginal issues. The characteristic feature of $\mathrm{THz}$ waves is their ability to penetrate through dielectric materials, such as plastics, ceramics, wood or textiles, which gives a possibility for nondestructive examination highly demanded for security systems and other remote control equipment. Moreover, they can be used for identification of hidden substances because many materials exhibit specific absorption features at $\mathrm{THz}$ frequencies. The $\mathrm{THz}$ radiation is especially attractive for analysis of biological objects since, due to its small photon energy, it does not modify the inspected item and is therefore absolutely safe. Besides the unique features of $\mathrm{THz}$ imaging this technology offers new horizons in communications. Compared with existing standards, a much larger bandwidth, ranging from tens of $\mathrm{GHz}$ up to several $\mathrm{THz}$ depending on the transmission distance, can be achieved in this frequency region. Realization of the high potential of the $\mathrm{THz}$ technology requires adequate instrumentation: radiation sources, detectors, and relevant components such as lenses, mirrors, filters, coating, modulators, etc. This conference deals with a wide range of topics covering all the issues related to the THz waves, from theory to components and applications.

A source of radiation is the main component of any spectroscopic or communication system. THz sources can be organized as pulsed or continuous (as for the operation), narrowband or broadband (spectral coverage), coherent or incoherent (radiation properties), or the working principle. Sources generating $\mathrm{THz}$ (directly) via oscillation in electronic (solid-state based or vacuum-based) or in optical devices (e.g. lasers) are denoted as direct. On the other hand, sources generating $\mathrm{THz}$ via nonlinear mixing or conversion of electromagnetic pump waves in a nonlinear medium or in medium with accelerating electrons are called indirect.

Vacuum electron devices are the most ancient emitters of $\mathrm{THz}$ radiation. Such sources are still widely used in research laboratories due to the high power and room temperature operation. A backward oscillator emitting up to $1 \mathrm{~W}$ of $\mathrm{THz}$ optical power was presented at the conference. This paper (SPIE number 10383-2, Gamzina, et al) describes the outstanding technological effort to design and realize a backward wave oscillator with $0.346 \mathrm{GHz}$ operating frequency to be employed in fusion plasma diagnostics. However, due mainly to the large footprint, the vacuum electron devices are not well suited for commercial use. Realization of on-chip, compact and mass producible THz sources will lead this technology to make a widespread social impact. 
Quantum cascade lasers (QCLs) are partially filling the $\mathrm{THz}$ gap of coherent sources, although cryogenic cooling and very limited tunability have restricted the number of spectroscopic applications. Room temperature operation is one of the main characteristics required in semiconductor lasers for mass scale applications. Unfortunately, THz QCLs have not yielded the room temperature action yet. The maximum operating temperature reported till date is $\sim 200 \mathrm{~K}$ for pulsed operation and $129 \mathrm{~K}$ for $\mathrm{CW}$ operation without using strong magnetic field. On the other hand, it is possible to fabricate RT THz emitters based on difference frequency generation (DFG) exploiting built-in nonlinear properties of mature high power mid-IR QCLs. This approach has been successfully employed by the Center for Quantum Devices directed by Prof. M. Razeghi in Northwestern University to demonstrate the best-todate QCL-based THz sources operating at room temperature. These DFG-QCL THz emitters exhibit RT optical powers up to $2 \mathrm{~mW}$ in pulsed mode and $14 \mu \mathrm{W}$ in the continuous wave regime. Such sources, as well as their application for frequency comb spectroscopy, have been reviewed in the keynote paper of Prof. Razeghi.

Compact solutions for spectroscopic solid-state based $\mathrm{THz}$ imaging systems are considered in several conference papers. To achieve compact and robust devices, a wide range of III- $\mathrm{V}$ semiconductors based materials for $1.55 \mu \mathrm{m} \mathrm{THz}$ photoconductive switches have been grown and optimized using various approaches by a research group from the University of Delaware. Relevant properties for the state-of-the-art materials for these devices including bandgap energy, dark resistance, carrier mobility, and carrier lifetime are discussed in this paper. Another paper on compact components for $\mathrm{THz}$ imaging is presented by the Center for Physical Sciences and Technology (Vilnius, Lithuania). Pulsed $\mathrm{THz}$ emitters based on a $\delta$-doped p-i-n-i GaAs/AlxGal-xAs heterostructure, on-chip integrated elements of diffractive optics and bow-tie-shaped InGaAs-based THz detectors were demonstrated and employed for direct and homodyne imaging of low absorbing objects.

Despite the fast advance in recent years, the potential of $\mathrm{THz}$ technology is still under-exploited due to the lack of practical devices for generation and detection of $\mathrm{THz}$ waves. We hope that the conference stimulates progress in this field and some new idea how to make $\mathrm{THz}$ technology as efficient and easy to use as near infrared one can be found in this volume.

\author{
Manijeh Razeghi \\ Alexei N. Baranov \\ Dimitris Pavlidis \\ John M. Zavada
}

